\title{
Fontes de Óleo Vegetal na Dieta de Cordeiros em Confinamento ${ }^{1}$
}

\section{Sandra Mari Yamamoto ${ }^{2}$, Francisco de Assis Fonseca de Macedo ${ }^{3}$, Marilice Zundt ${ }^{4}$, Alexandre Agostinho Mexia ${ }^{4}$, Eduardo Shiguero Sakaguti ${ }^{3}$, Guilherme Bareia Liberato Rocha ${ }^{5}$, Kelly Cristina Telles Regaçoni ${ }^{5}$, Rosa Maria Gomes de Macedo ${ }^{3}$}

\begin{abstract}
RESUMO - Objetivou-se avaliar a ingestão de matéria seca, o ganho de peso diário, a conversão alimentar, o peso vivo ao abate e

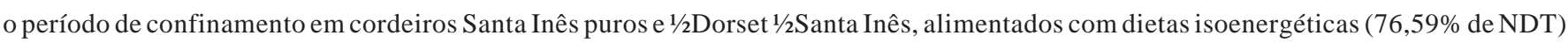
e isoprotéicas (17,48\% de PB) contendo diferentes fontes de óleo vegetal (óleos de soja, canola e linhaça) e uma dieta controle (sem inclusão de óleo vegetal). A relação volumoso:concentrado foi de 30:70 e utilizou-se feno de aveia como volumoso. Realizou-se também um ensaio de digestibilidade, utilizando quatro cordeiros não-castrados, distribuídos em delineamento quadrado latino, avaliando-se ingestão, excreção fecal e digestibilidade total dos nutrientes das rações. A ingestão de matéria seca, expressa em porcentagem do peso vivo, foi menor nos cordeiros que receberam dieta contendo óleo de canola que naqueles que receberam dieta controle. Porém, todas as rações proporcionaram ganhos de peso e conversão alimentar satisfatórios. Os valores de digestibilidade total da matéria seca (76,02\%) e matéria orgânica $(76,82 \%)$ da dieta controle foram superiores aos da dieta contendo óleo de linhaça (72,11\% e 72,97\%, respectivamente), embora não tenham diferido das dietas contendo óleos de soja (72,94 e 73,71\%) e canola $(73,45$ e 74,25\%). A digestibilidade do extrato etéreo foi menor na dieta controle $(84,02 \%)$, enquanto as demais dietas apresentaram valor médio de $91,98 \%$. Os óleos vegetais reduziram a digestibilidade da matéria seca e da matéria orgânica, não afetando a ingestão e digestão dos demais nutrientes.
\end{abstract}

Palavras-chave: consumo, digestibilidade, ganho de peso

\section{Vegetable Oil Sources in Feedlot Lambs}

\begin{abstract}
This experiment was carried out to evaluate the dry matter ingestion, average daily gain, feed:gain ratio, live weight at slaughter and days in trial in pure Santa Inês and $1 \frac{2}{2}$ Dorset $1 \frac{2}{2}$ Santa Inês lambs, submitted to isoenergetic (76.59\% TDN) and isoprotein ( $17.48 \%$ crude protein) diets with different sources of vegetable oil (soybean oil, canola and linseed) and a control diet (without vegetable oil inclusion). The forage:concentrate ratio was 30:70, and oat hay was used as forage. Digestibility analysis was performed, using four no castrated lambs distributed in latin square design, for evaluating ingestion, fecal excretion and total digestibility of the nutrients. The dry matter intake, expresses in percentage of the live weight, was smaller in the lambs that received diet with canola oil in relation to those that received control diet. However, all the diets provided satisfactory average weight gain and feed:gain ratio. The dry matter $(76.02 \%)$ and organic matter $(76.82 \%)$ total digestibility values of the control diet were higher than diet with linseed oil $(72.11 \%$ and $72.97 \%$, respectively), although they have not difference of the diets with soybean $(72.94$ and $73.71 \%)$ and canola oils $(73.45$ and $74.25 \%)$ and these did not differ of the diet with linseed oil. Digestibility of ether extract was smaller in the control diet $(84.02 \%)$, while the other diets showed average value of $91.98 \%$. The vegetable oils reduced the digestibility of dry and organic matter, not affecting the digestion of the other nutrients.
\end{abstract}

Key Words: digestibility, intake, weight gain

\section{Introdução}

A ovinocultura na região Centro-Sul do Brasil vem crescendo nos últimos anos e tem como finalidade a produção de cordeiros para abate. O sistema intensivo adotado na terminação de cordeiros com dietas contendo elevada concentração energética pode diminuir o tempo necessário para os animais atingirem o peso de abate, minimizando os problemas sanitários.
Por outro lado, este tipo de sistema eleva o custo total de produção, principalmente com alimentação, exigindo material genético de elevado potencial de crescimento para reduzir ao máximo o tempo de permanência no confinamento.

As raças utilizadas pelos produtores do Paraná, antes predominantemente lanadas, tem sido substituídas por raças deslanadas, com predominância para a Santa Inês. No entanto, existem algumas caracterís-

\footnotetext{
1 Parte da dissertação do primeiro autor. Projeto financiado pelo CNPq.

2 Aluna de Doutorado em Zootecnia (Produção Animal) da FCAV/Unesp, Jaboticabal, SP. Rua Carlos Buck, 184, Bairro Santa Tereza, CEP: 14883-292, Jaboticabal, SP. E.mail: yamamoto@fcav.unesp.br

3 Professores do Departamento de Zootecnia da Universidade Estadual de Maringá - UEM, PR.

${ }^{4}$ Alunos de Doutorado em Zootecnia da UEM.

${ }^{5}$ Alunos do curso de graduação em Zootecnia da UEM.
} 
ticas consideradas indesejáveis nesta raça, no tocante à produção de carne: seus cordeiros apresentam menor velocidade de ganho de peso e carcaça de pior conformação que os das raças lanadas especializadas na produção de carne. Entretanto, essas características podem ser melhoradas com a utilização de reprodutores das raças de corte lanadas, para produção de cordeiros com vigor híbrido, melhorando o ganho de peso e a conformação da carcaça. Os reprodutores disponíveis no Brasil mais indicados para o cruzamento com ovelhas Santa Inês são os das raças Dorper ou Dorset, pois as fêmeas de ambas as raças, como as Santa Inês, manifestam cios durante todo o ano e proporcionam melhor conformação de carcaças aos seus descendentes.

Mudanças advindas da estabilidade econômica, do poder aquisitivo, da preocupação com saúde e bem-estar, entre outros fatores, vêm contribuindo de forma marcante para que o consumidor se torne mais exigente na busca de produtos que atendam aos seus anseios (Luchiari Filho, 1998). Nos últimos anos, temse verificado interesse crescente dos consumidores no efeito benéfico à saúde de determinados alimentos, exigindo que, além de satisfazer às necessidades nutritivas básicas, forneçam um benefício fisiológico adicional (Hasler, 1998), o que tem estimulado a indústria da carne e os pesquisadores da ciência da carne a procurarem soluções.

Os ácidos linoléico (C18:2) e linolênico (C18:3), os principais ácidos graxos dos vegetais, podem ser encontrados em quantidades muito pequenas na gordura corporal dos ruminantes e são tidos como essenciais, por não serem sintetizados pelos animais, devendo fazer parte da dieta dos mesmos. Estão presentes em abundância em óleos vegetais como os de girassol, canola, soja e linhaça e sua concentração no leite e na carne de bovinos pode ser elevada se os animais forem alimentados com dietas ricas em óleo de cereais e sementes (Demeyer \& Doreau, 1999).

O consumo de matéria seca é uma importante variável que afeta o desempenho animal, uma vez que engloba a ingestão de todos os nutrientes e determina a resposta animal (Barros et al., 1997). A taxa de consumo voluntário sofre influência da qualidade do alimento, podendo se tornar um fator limitante mesmo que o valor nutritivo seja adequado.
A importância do conhecimento do valor nutritivo dos alimentos, assim como da utilização dos nutrientes, é reconhecida quando se tem como objetivo alcançar o potencial máximo produtivo e reprodutivo dos animais. A digestibilidade também deve ser considerada, pois dos nutrientes absorvidos provém a capacidade do animal em manter suas funções vitais, necessidades energéticas e formação de produtos. Em experimentos em que a gordura é adicionada à dieta de ruminantes, seja para aumentar o valor energético ou para reduzir o custo da ração, observase geralmente redução na digestibilidade da parede celular (Villaça et al., 1999).

Objetivou-se, com este trabalho, avaliar o desempenho e a digestibilidade dos nutrientesem cordeiros Santa Inês puros e 1/2Dorset $1 / 2$ Santa Inês terminados em confinamento, consumindo dietas contendo diferentes fontes de óleo vegetal.

\section{Material e Métodos}

Foram utilizados 24 cordeiros machos inteiros 13 Santa Inês puros (SI) e 11 1/2Dorset $1 / 2$ Santa Inês (DS) - desmamados aos 60 dias de idade e com peso inicial de $15,81 \pm 1,50 \mathrm{~kg}$. Os animais foram criados, desde o nascimento, em instalações cobertas com piso ripado suspenso, com disponibilidade, a partir da terceira semana de vida, de ração no creep feeding com 18,20\% de proteína bruta (PB); 3,0 Mcal de energia metabolizável (EM)/kg de matéria seca; $1,46 \%$ de cálcio e $1,00 \%$ de fósforo. Todos os animais foram identificados e distribuídos conforme grupo genético e peso, em quatro dietas. As dietas utilizadas foram: ração sem adição de óleo vegetal (controle); com adição de óleo de soja (soja); com adição de óleo de canola (canola) e com adição de óleo de linhaça (linhaça). As dietas foram peletizadas e continham, em média, $17,48 \%$ de PB e $76,59 \%$ de nutrientes digestíveis totais (NDT) (Tabela 1).

Os animais permaneceram em baias individuais (cobertas, com piso ripado e suspenso, equipadas com comedouros individuais e bebedouros coletivos para cada dois animais) e receberam água à vontade, durante todo o período experimental. Foram pesados no início do experimento e a cada 14 dias, para determinação do ganho de peso médio diário. As rações foram fornecidas uma vez ao dia, sendo pesadas diariamente e ajustadas 
Tabela 1 - Composições percentual e bromatológica (\% MS) e custo das dietas experimentais Table 1 - Percentage, chemical composition and cost of the experimental diets

\begin{tabular}{|c|c|c|c|c|}
\hline \multirow[b]{2}{*}{$\begin{array}{l}\text { Ingrediente (\%) } \\
\text { Ingredient (\%) }\end{array}$} & \multicolumn{4}{|c|}{$\operatorname{Dieta}($ Diet $)$} \\
\hline & $\begin{array}{c}\text { Controle } \\
\text { Control }\end{array}$ & $\begin{array}{c}\text { Soja } \\
\text { Soybean }\end{array}$ & $\begin{array}{l}\text { Canola } \\
\text { Canola }\end{array}$ & $\begin{array}{l}\text { Linhaça } \\
\text { Linseed }\end{array}$ \\
\hline $\begin{array}{l}\text { Feno de aveia } \\
\text { Oat hay }\end{array}$ & 25,10 & 32,00 & 32,00 & 32,00 \\
\hline Milho moído & 53,40 & 42,00 & 42,00 & 42,00 \\
\hline $\begin{array}{l}\text { Corn grain ground } \\
\text { Farelo de soja } \\
\text { Soybean meal }\end{array}$ & 20,00 & 21,50 & 21,50 & 21,50 \\
\hline $\begin{array}{l}\text { Calcário } \\
\text { Limestone }\end{array}$ & 1,00 & 1,00 & 1,00 & 1,00 \\
\hline $\begin{array}{l}\text { Sal comum } \\
\text { Salt }\end{array}$ & 0,50 & 0,50 & 0,50 & 0,50 \\
\hline $\begin{array}{l}\text { Óleo de soja } \\
\text { Soybean oil }\end{array}$ & - & 3,00 & - & - \\
\hline $\begin{array}{l}\text { Óleo de canola } \\
\text { Canola oil }\end{array}$ & - & - & 3,00 & - \\
\hline $\begin{array}{l}\text { Óleo de linhaça } \\
\text { Linseed oil } \\
\text { Nutriente } \\
\text { Nutrient }\end{array}$ & - & - & - & 3,00 \\
\hline $\begin{array}{l}\text { Matéria seca }(\mathrm{MS}) \\
\text { Dry matter }(D M)\end{array}$ & 91,58 & 92,12 & 91,92 & 91,79 \\
\hline $\begin{array}{l}\text { Proteína bruta }(\mathrm{PB}) \\
\text { Crude protein }(C P)\end{array}$ & 17,18 & 17,80 & 17,44 & 17,52 \\
\hline $\begin{array}{l}\text { Extrato etéreo }(\mathrm{EE}) \\
\text { Ether extract }(E E)\end{array}$ & 2,30 & 5,09 & 5,40 & 5,00 \\
\hline $\begin{array}{l}\text { Fibra detergente neutro (FDN) } \\
\text { Neutral detergent fiber (NDF) }\end{array}$ & 25,56 & 28,72 & 29,47 & 29,98 \\
\hline $\begin{array}{l}\text { Matéria mineral }(\mathrm{MM}) \\
\text { Mineral matter }(M M)\end{array}$ & 5,11 & 5,59 & 5,50 & 5,56 \\
\hline $\begin{array}{l}\text { NDT } \\
T D N\end{array}$ & 76,07 & 76,87 & 77,68 & 75,75 \\
\hline $\begin{array}{l}\text { Custo }(\mathrm{R} \$ / \mathrm{kg}) \\
\text { Cost }(U \$ / \mathrm{kg}) *\end{array}$ & $\begin{array}{l}0,2388 \\
0,0708\end{array}$ & $\begin{array}{l}0,2733 \\
0,0811\end{array}$ & $\begin{array}{l}0,3057 \\
0,0907\end{array}$ & $\begin{array}{l}0,3216 \\
0,0954\end{array}$ \\
\hline
\end{tabular}

*Cotação do dólar em 20/01/2003: R\$3,37= U\$1,00.

de acordo com o peso médio dos animais, de forma a permitir $20 \%$ de sobras. O consumo de ração foi determinado, descontando-se as sobras diárias do total fornecido, estimando-se, seqüencialmente, a conversão alimentar.

Quando os cordeiros atingiram aproximadamente $30 \mathrm{~kg}$ de peso vivo, foram submetidos a jejum de sólidos por 18 horas e pesados, obtendo-se, assim, o peso vivo ao abate (PVA).

$\mathrm{O}$ delineamento experimental foi em blocos casualizados, utilizando-se o peso inicial como fator de blocagem, decomposto em modelo fatorial $4 \times 2$ (quatro dietas e dois grupos genéticos). As variáveis estudadas foram submetidas à análise de variância (SAS, 1996) de acordo com o seguinte modelo:

$$
Y_{i j k}=m+T_{i}+G_{j}+T_{i j}+B_{k}+e_{i j k} \text {, }
$$

em que: $\mathrm{Y}_{\mathrm{ijk}}=$ valor observado da variável estudada no indivíduo k, pertencente ao grupo genético j, recebendo a dieta $\mathrm{i} ; \mathrm{m}=$ constante associada às observações; $\mathrm{T}_{\mathrm{i}}=$ efeito da dieta $\mathrm{i}$, variando de 1 a $4 ; \mathrm{G}_{\mathrm{j}}=$ efeito do grupo genético $\mathrm{j}$, variando de 1 a $2 ; \mathrm{TG}_{\mathrm{ij}}=$ interação entre dieta e grupo genético; $\mathrm{B}_{\mathrm{k}}=$ efeito do bloco $\mathrm{k}$, variando de 1 a $2 ; \mathrm{e}_{\mathrm{ijk}}=$ erro aleatório associado a cada observação $\mathrm{Y}_{\mathrm{ijk}}$.

As médias foram comparadas pelo teste Tukey a $5 \%$ de probabilidade.

Para o ensaio de digestibilidade, foram utilizados quatro cordeiros machos inteiros (dois Santa Inês puros e dois $1 / 2$ Dorset $1 / 2$ Santa Inês), com peso vivo de $23,65 \pm 0,75 \mathrm{~kg}$. Os animais foram colocados em baias individuais e adaptados ao uso de sacolas para coleta 
total de fezes, que foram coletadas e pesadas diariamente pela manhã, homogeneizadas, retirando-se amostras de $10 \%$ do total, sendo, então acondicionadas em embalagens de polietileno e congeladas para posterior análise laboratorial.

O delineamento adotado neste ensaio foi o quadrado latino $4 \times 4$, com quatro dietas e quatro períodos. Para cada período experimental de 15 dias, 10 dias foram destinados à adaptação às rações e cinco, à coleta, nos quais foram amostradas as fezes, sobras e rações fornecidas.

As amostras das rações fornecidas, sobras e fezes foram pré-secas em estufa de ventilação forçada a $55^{\circ} \mathrm{C}$, por 72 horas. Posteriormente, foram processadas em moinho martelo, com peneiras de $1 \mathrm{~mm}$ de diâmetro, para determinação dos teores de matéria seca (MS), proteína bruta (PB), matéria mineral (MM), extrato etéreo (EE) e fibra em detergente neutro (FDN), conforme metodologias descritas por Silva (1990). Os valores de carboidratos não-fibrosos (CNF) foram obtidos pela diferença entre carboidratos totais (CHOT) e FDN, sendo CHOT obtido a partir da equação $100-(\% \mathrm{~PB}+\% \mathrm{EE}+\%$ Cinzas $)$, de acordo com Sniffen et al. (1992). Os teores de nutrientes digestíveis totais foram estimados pela seguinte equação: NDT = PBdigestível + FBdigestível + (EEdigestívelx 2,25) + CNFdigestível (Sniffen et al., 1992).

Os dados foram analisados por intermédio do Sistema de Análises Estatísticas (SAS, 1996), de acordo com o seguinte modelo:

$$
Y_{i j k}=m+T_{i}+A_{j}+P_{k}+e_{i j k}
$$

em que: $Y_{i j k}=$ valor observado da variável estudada no indivíduo j, pertencente ao período $\mathrm{k}$, recebendo a dieta $\mathrm{i} ; \mathrm{m}=$ constante associada às observações; $\mathrm{T}_{\mathrm{i}}=$ efeito da dieta $i$, variando de 1 a $4 ; \mathrm{A}_{\mathrm{j}}=$ efeito do animal $j$, variando de 1 a $4 ; \mathrm{P}_{\mathrm{k}}=$ efeito do período $k$, variando de 1 a $4 ; \mathrm{e}_{\mathrm{ijk}}=$ erro aleatório associado a cada observação $\mathrm{Y}_{\mathrm{ijk}}$.

\section{Resultados e Discussão}

Na Tabela 2, encontram-se os resultados de desempenho dos cordeiros terminados em confinamento,

Tabela 2 - Médias e erros-padrão para peso inicial (PI), peso ao abate (PA), ingestão de matéria seca (IMS), ganho de peso diário (GPD), conversão alimentar (CA) e período de confinamento (PC), de acordo com as dietas e grupos genéticos

Table 2 - Means and standard errors of initial weight (IW), slaughter weight (SW), dry matter intake (DMI), daily weight gain (DWG), feed: gain ratio ( $F: G)$ and days in trial $(D T)$, according to the diets and genetic groups

\begin{tabular}{|c|c|c|c|c|c|c|c|}
\hline \multirow[b]{2}{*}{$\begin{array}{l}\text { Variável } \\
\text { Variable }\end{array}$} & \multicolumn{4}{|c|}{$\begin{array}{l}\text { Dieta } \\
\text { Diet }\end{array}$} & \multicolumn{2}{|c|}{$\begin{array}{l}\text { Grupo genético } \\
\text { Genetic group }\end{array}$} & \multirow[b]{2}{*}{$\mathrm{CV}(\%)$} \\
\hline & $\begin{array}{c}\text { Controle } \\
\text { Control }\end{array}$ & $\begin{array}{c}\text { Soja } \\
\text { Soybean }\end{array}$ & $\begin{array}{l}\text { Canola } \\
\text { Canola }\end{array}$ & $\begin{array}{l}\text { Linhaça } \\
\text { Linseed }\end{array}$ & $\mathrm{SI}^{1}$ & $\mathrm{DS}^{2}$ & \\
\hline $\begin{array}{l}\mathrm{PI}(\mathrm{kg}) \\
I W(\mathrm{~kg})\end{array}$ & $15,92 \pm 0,66$ & $15,22 \pm 0,62$ & $17,22 \pm 0,62$ & $14,91 \pm 0,62$ & $15,63 \pm 0,42$ & $16,01 \pm 0,46$ & 9,53 \\
\hline $\begin{array}{l}\mathrm{PA}(\mathrm{kg}) \\
S W(\mathrm{~kg})\end{array}$ & $29,46 \pm 0,38^{b}$ & $29,83 \pm 0,36^{\mathrm{b}}$ & $30,98 \pm 0,35^{\mathrm{a}}$ & $29,57 \pm 0,35^{\mathrm{b}}$ & $29,54 \pm 0,25^{\mathrm{b}}$ & $30,53 \pm 0,26^{a}$ & 2,91 \\
\hline $\begin{array}{l}\text { IMS (kg/dia) } \\
D M I \text { (kg/day) }\end{array}$ & $1,04 \pm 0,03$ & $0,98 \pm 0,03$ & $0,98 \pm 0,03$ & $0,97 \pm 0,03$ & $0,97 \pm 0,02$ & $1,01 \pm 0,02$ & 6,23 \\
\hline $\begin{array}{l}\mathrm{IMS}(\% \mathrm{PV}) \\
D M I(\% L W)\end{array}$ & $4,55 \pm 0,12^{\mathrm{a}}$ & $4,20 \pm 0,11^{\mathrm{ab}}$ & $4,05 \pm 0,11^{\mathrm{b}}$ & $4,24 \pm 0,11^{\mathrm{ab}}$ & $4,23 \pm 0,07$ & $4,29 \pm 0,08$ & 6,26 \\
\hline $\begin{array}{l}\text { IMS }\left(\mathrm{g} / \mathrm{kg}^{0,75} / \mathrm{dia}\right) \\
D M I\left(\mathrm{~g} / \mathrm{kg}^{0.75} / \text { day }\right)\end{array}$ & $91,91 \pm 4,78$ & $90,82 \pm 4,54$ & $89,44 \pm 4,54$ & $93,06 \pm 4,54$ & $93,10 \pm 4,54$ & $89,51 \pm 3,36$ & 11,86 \\
\hline $\begin{array}{l}\mathrm{GPD}(\mathrm{kg} / \text { dia }) \\
D W G \quad(\mathrm{~kg} / \text { day })\end{array}$ & $0,297 \pm 0,01^{\mathrm{a}}$ & $0,272 \pm 0,01^{\mathrm{ab}}$ & $0,262 \pm 0,01^{\mathrm{ab}}$ & $0,245 \pm 0,01^{\mathrm{b}}$ & $0,258 \pm 0,01$ & $0,280 \pm 0,01$ & 12,94 \\
\hline $\begin{array}{l}\text { CA } \\
F: G\end{array}$ & $3,50 \pm 0,16$ & $3,57 \pm 0,15$ & $3,89 \pm 0,15$ & $3,95 \pm 0,15$ & $3,82 \pm 0,10$ & $3,64 \pm 0,11$ & 9,78 \\
\hline $\begin{array}{l}\mathrm{PC} \text { (dias) } \\
D T(\text { days })\end{array}$ & $42,98 \pm 3,90$ & $50,69 \pm 3,71$ & $51,48 \pm 3,71$ & $54,52 \pm 3,71$ & $51,87 \pm 2,50$ & $47,95 \pm 2,74$ & 17,81 \\
\hline
\end{tabular}

${ }^{1} \mathrm{SI}=$ Santa Inês; ${ }^{2} \mathrm{DS}=1 / 2$ Dorset $1 / 2$ Santa Inês.

* Médias seguidas por letras distintas, na linha, diferem entre dietas, pelo teste Tukey $(p>0,05)$.

*Médias seguidas por letras distintas, na linha, diferem entre grupos genéticos, pelo teste Tukey $(p>0,05)$.

* Means followed by different letter, within a row, are different ( $p>$.05) among diets, by Tukey test.

*Means followed by different letter, within a row, are different ( $p>$.05) among genetic groups, by Tukey test. 
de acordo com as dietas e os grupos genéticos. Não houve interação entre dietas e grupos genéticos para as variáveis avaliadas.

A ingestão média de matéria seca, expressa em $\mathrm{kg} / \mathrm{dia}(0,990 \mathrm{~kg} / \mathrm{dia})$, foi inferior à encontrada por Mir et al. (2000), em cordeiros alimentados com ração sem adição de óleo vegetal (1,53 kg de MS/dia) e com adição de $6 \%$ de óleo vegetal $(1,21 \mathrm{~kg} / \mathrm{dia})$, ambas contendo $16,6 \%$ de proteína bruta. Entretanto, a ingestão observada foi semelhante à relatada por Rocha et al. (2001), que trabalharam com cordeiros Santa Inês mestiços, com idade média inicial de 86 dias e peso inicial de $18,4 \mathrm{~kg}$, alimentados com dietas contendo níveis crescentes de proteína bruta (14, 16, 18 e 20\%).

Alves et al. (2002a), avaliando o consumo de ovinos Santa Inês terminados em confinamento com diferentes níveis de energia, registraram valores de 0,900; 0,870 e $0,870 \mathrm{~kg} / \mathrm{dia}$, para níveis de 2,42; 2,66 e 2,83 Mcal de EM/kg de MS, respectivamente, inferiores aos encontrados neste experimento. Entretanto, a ingestão de matéria seca pelos cordeiros do presente estudo encontra-se próxima da média recomendada pelo NRC (1985) para ovinos desta categoria, que é de 1,0 a $1,3 \mathrm{~kg} \mathrm{MS} /$ animal/dia.

Quando expressa em porcentagem do peso vivo, os cordeiros alimentados com dieta controle tiveram maior ingestão $(4,55 \%)$ que aqueles que receberam dieta contendo óleo de canola $(4,05 \%)$, o que pode ser explicado pelo fato de esta dieta apresentar maior teor energético que a dieta controle, limitando a ingestão de matéria seca. Estes resultados são superiores aos 3,17\% reportados por Marques (2003) ao trabalhar com cordeiros 7/8Ile de France 1/8Ideal alimentados com dietas contendo relações volumoso:concentrado de 50:50 e 30:70, provavelmente por a dieta fornecida no presente experimento ser peletizada, favorecendo a ingestão.

O ganho de peso diário dos cordeiros alimentados com dieta controle foi superior $(0,297 \mathrm{~kg} / \mathrm{dia})$ ao dos alimentados com dieta contendo óleo de linhaça $(0,245$ $\mathrm{kg} / \mathrm{dia})$, que não diferiu $(\mathrm{p}>0,05)$ do ganho dos que receberam dieta contendo óleos de soja $(0,272 \mathrm{~kg} / \mathrm{dia})$ e de canola $(0,262 \mathrm{~kg} / \mathrm{dia})$. Todos as dietas proporcionaram ganhos superiores aos encontrados por Pérez et al. (1998), ao trabalharem com cordeiros Santa Inês alimentados com dieta contendo $83 \%$ de concentrado e $18 \%$ de PB.

Mir et al. (2000), estudando cordeiros mestiços Suffolk x Dorset alimentados com ração peletizada suplementada com óleo de açafrão (6\% na MS) por
80 dias em confinamento, abatidos aos 45,90 kg, encontraram ganhos de peso de $0,380 \mathrm{~kg} /$ dia para cordeiros que receberam ração controle (sem adição de óleo) e 0,349 kg/dia para cordeiros que receberam ração com adição de óleo, resultados superiores aos encontrados neste trabalho. Ganhos de peso semelhantes aos encontrados neste experimento foram obtidos por Preziuso et al. (1999), em cordeiros da raça Apennine, recebendo dietas contendo 5\% de óleo de milho $(0,260 \mathrm{~kg} / \mathrm{dia})$ com $18,26 \%$ de PB e $6,27 \%$ de EE na matéria seca e abatidos com peso vivo médio de $33 \mathrm{~kg}$.

Para conversão alimentar, os dados obtidos neste trabalho foram melhores que os 9,6; 8,4 e 7,0 registrados por Alves et al. (2002a), utilizando ovinos Santa Inês terminados em confinamento, recebendo diferentes níveis de energia. Garcia et al. (2000) e Rocha et al (2001) também verificaram piores índices de conversão alimentar $(4,31$ e 6,50) em cordeiros mestiços Santa Inês. Preziuso et al. (1999) relataram índices de conversão de 4,52; 4,77 e 4,61 para cordeiros recebendo uma dieta sem adição de óleo e duas dietas contendo $5 \%$ de óleo de milho.

Neste estudo, embora a dieta tenha afetado o ganho médio diário de peso, a mesma não afetou a conversão alimentar, pelo fato de o ganho peso diário ser uma medida direta e a conversão alimentar ser uma medida indireta (kg MS ingerida/GPD), resultando na diluição das médias.

O período médio de confinamento foi de 50 dias, permitindo que os cordeiros fossem terminados precocemente, uma vez que adentraram no experimento com média de 75 dias de idade. Este resultado mostrou-se satisfatório, pois carcaças de cordeiros precoces (abatidos de 120 a 150 dias de idade) apresentam menor quantidade de gordura, atendendo às exigências do mercado consumidor (Carvalho \& Siqueira, 2001).

Os resultados para eficiência alimentar encontram-se nas Tabelas 3 e 4 . A ingestão e excreção fecal (g/dia) de MS, MO, PB, FDN, CNE e NDT foram semelhantes entre as dietas. Este mesmo perfil não foi observado para ingestão e digestão de EE, que apresentou dados inferiores para a dieta controle, podendo ser explicado pelo baixo teor de EE (2,30\%) presente na ração (Tabela 1).

Os valores de digestibilidade total da MS (76,02\%) e MO $(76,82 \%)$ da dieta controle foram superiores $(\mathrm{p}<0,05)$ aos da dieta contendo óleo de linhaça $(72,11$ e $72,97 \%$, respectivamente), embora não tenham di- 
Tabela 3 - Médias e erros-padrão para ingestão (ING), excreção fecal (EF) e digestibilidade total (DIGT) da matéria seca, matéria orgânica e proteína bruta

Table 3 - Means and standard errors for intake (INT), feces excretion (FE) and total digestibility (TDIG) of dry matter, organic matter and crude protein

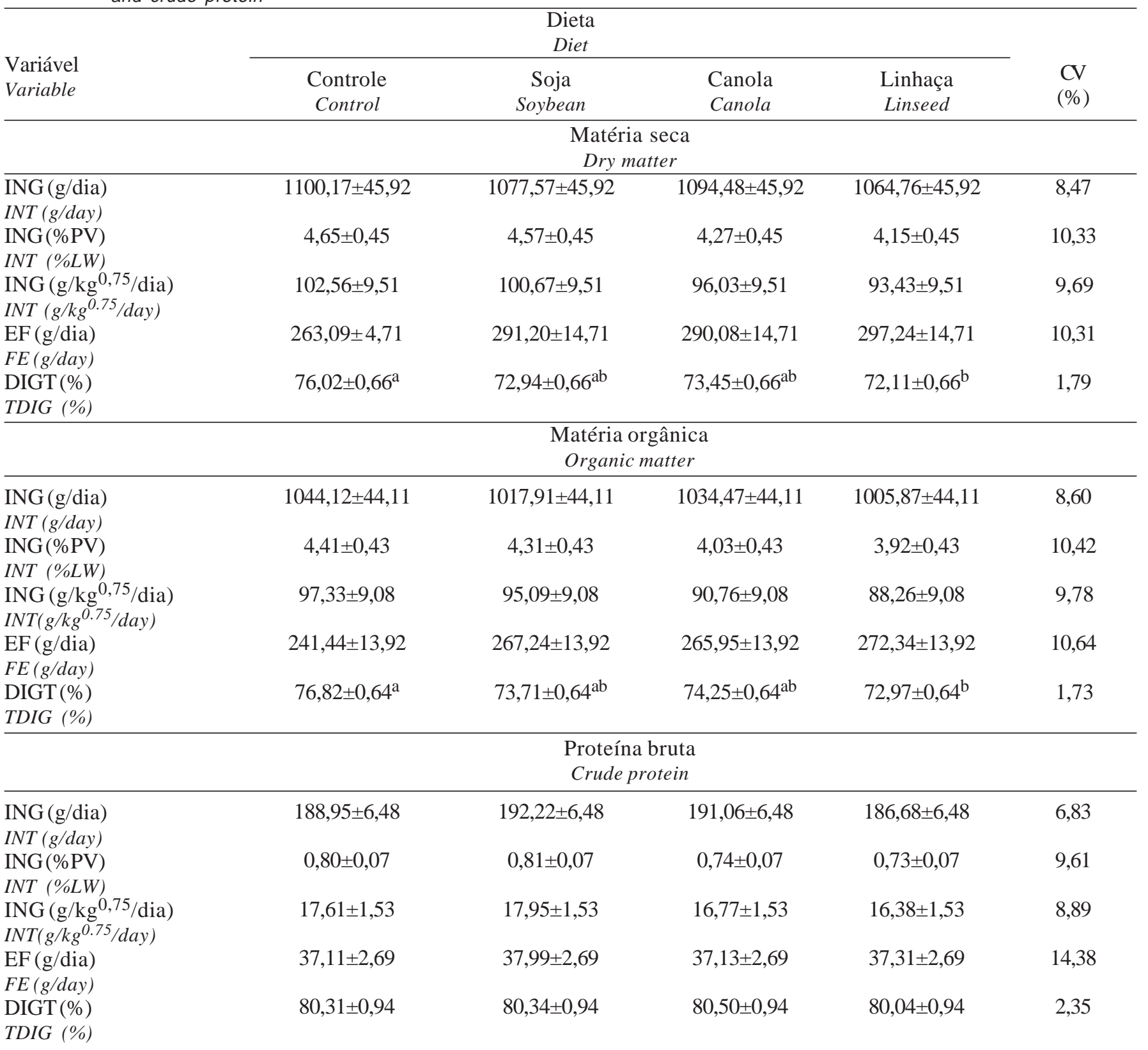

Médias seguidas por letras distintas na linha diferem $(p<0,05)$ entre si pelo teste Tukey.

Means followed by the different letters, within a row, are different $(p<.05)$ by Tukey test.

ferido ( $\mathrm{p}>0,05)$ das dietas com inclusão de óleos de soja $(73,94$ e $73,71 \%)$ e de canola $(73,45$ e $74,25 \%)$ e estes não diferiram $(\mathrm{p}>0,05)$ da dieta com óleo de linhaça. A digestibilidade do EE foi menor na dieta controle $(84,02 \%)$, enquanto as demais dietas apresentaram valores semelhantes, com média de $91,98 \%$.

Villaça et al. (1999), estudando o efeito da adição de óleo de soja (2,9\% da ração total) em ensaio de digestibilidade in vitro, verificaram redução de 9,4\% e 15,9\% sobre a digestibilidade da MS e da FDA, respectivamente. A digestibilidade da MS na ração sem adição de óleo foi de 74,08\% enquanto, naquela com adição de óleo de soja, foi de $67,09 \%$, valores inferiores aos encontrados neste trabalho.

Avaliando o efeito dos níveis de energia em dietas para ovinos Santa Inês sobre a digestibilidade aparente de nutrientes, Alves et al. (2002b) encontraram valores médios de coeficientes de digestibilidade de 
Tabela 4 - Médias e erros-padrão para ingestão (ING), excreção fecal (EF) e digestibilidade total (DIGT) da fibra em detergente neutro, extrato etéreo, carboidratos não-fibrosos e nutrientes digestíveis totais

Table 4 - Means and standard errors for intake (INT), feces excretion (FE) and total digestibility (TDIG) of neutral detergent fiber, ether extract, nonfiber carbohydrates and total digestible nutrients

\begin{tabular}{|c|c|c|c|c|c|}
\hline \multirow[b]{2}{*}{$\begin{array}{l}\text { Variável } \\
\text { Variable }\end{array}$} & \multicolumn{4}{|c|}{$\begin{array}{l}\text { Dieta } \\
\text { Diet }\end{array}$} & \multirow[b]{2}{*}{$\begin{array}{l}\mathrm{CV} \\
(\%)\end{array}$} \\
\hline & $\begin{array}{l}\text { Controle } \\
\text { Control }\end{array}$ & $\begin{array}{c}\text { Soja } \\
\text { Soybean }\end{array}$ & $\begin{array}{l}\text { Canola } \\
\text { Canola }\end{array}$ & $\begin{array}{l}\text { Linhaça } \\
\text { Linseed }\end{array}$ & \\
\hline \multicolumn{6}{|c|}{$\begin{array}{l}\text { Fibra em detergente neutro } \\
\text { Neutral detergent fiber }\end{array}$} \\
\hline $\begin{array}{l}\mathrm{ING}(\% \mathrm{PV}) \\
I N T(\% L W)\end{array}$ & $1,19 \pm 0,11$ & $1,30 \pm 0,11$ & $1,25 \pm 0,11$ & $1,24 \pm 0,11$ & 9,06 \\
\hline $\begin{array}{l}\mathrm{ING}\left(\mathrm{g} / \mathrm{kg}^{0,75} / \mathrm{dia}\right) \\
\operatorname{INT}\left(\mathrm{g} / \mathrm{kg}^{0.75} / \text { day }\right)\end{array}$ & $26,20 \pm 8,96$ & $28,77 \pm 8,96$ & $28,24 \pm 8,96$ & $27,87 \pm 8,96$ & 2,48 \\
\hline $\begin{array}{l}\mathrm{EF}(\mathrm{g} / \mathrm{dia}) \\
F E(g / \text { day })\end{array}$ & $170,23 \pm 9,23$ & $192,31 \pm 9,23$ & $191,42 \pm 9,23$ & $193,36 \pm 9,23$ & 9,87 \\
\hline
\end{tabular}

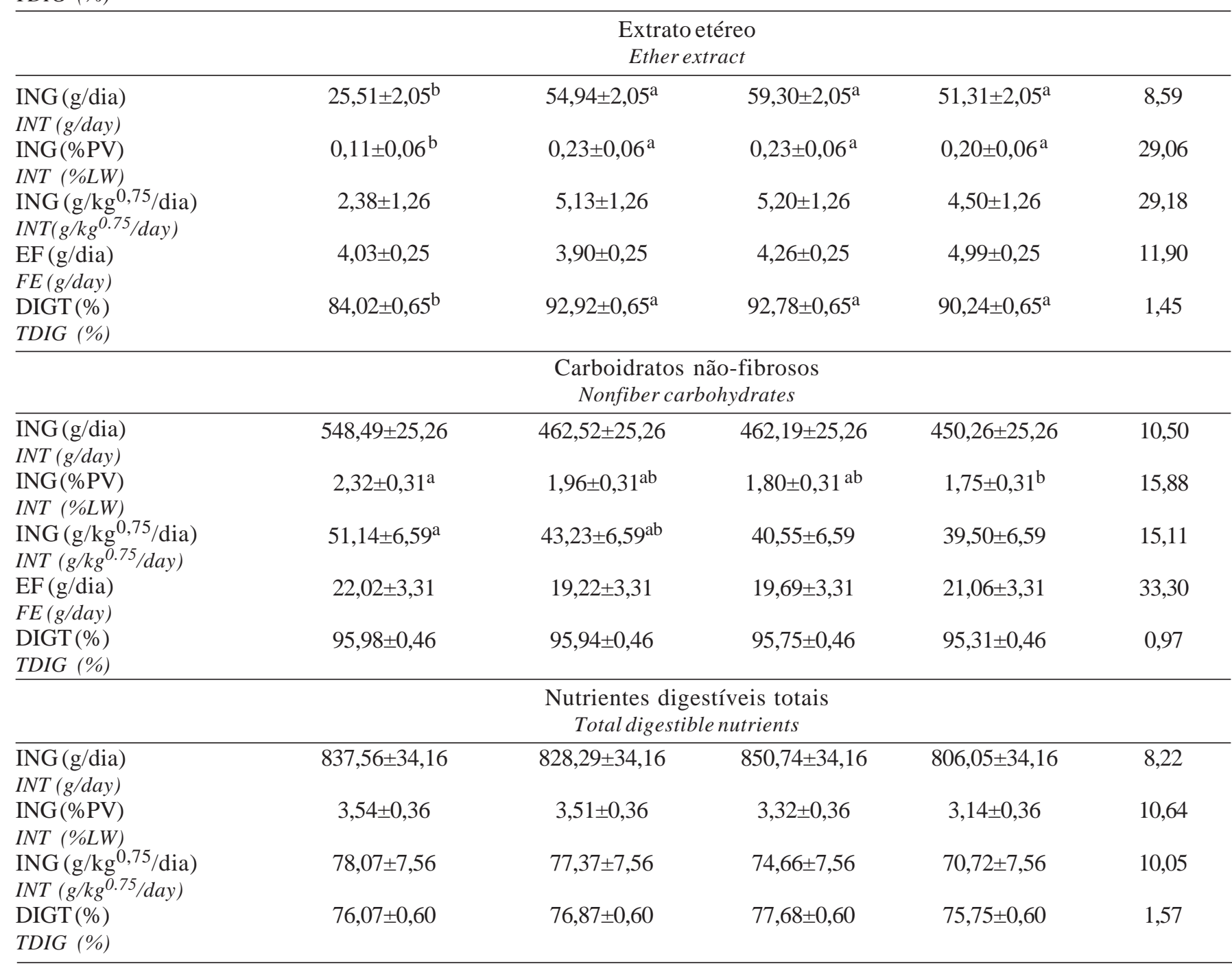


$72,76 \%$ para MS e 74,92\% para MO, valores semelhantes aos encontrados neste experimento. Entretanto, para a digestibilidade da PB, EE e NDT, estes autores registraram valores de 77,62, 68,55 e 72,98\%, respectivamente, inferiores ao encontrados neste trabalho. Para a digestibilidade da FDN, o valor encontrado por Alves et al. (2002b) foi de 59,71\%, superior ao observado neste trabalho, provavelmente pelo fato de as dietas utilizadas por estes pesquisadores possuírem maior teor de FDN.

\section{Conclusões}

Dietas peletizadas com inclusão de óleos vegetais proporcionaram desempenho satisfatório na terminação de cordeiros em confinamento, embora com ganhos inferiores para aqueles alimentados com dieta contendo óleo de linhaça, provavelmente devido à menor digestibilidade da matéria seca desta dieta.

\section{Literatura Citada}

ALVES, K.S.; CARVALHO, F.F.R.; VÉRAS, A.S.C. Efeito dos níveis de energia em dietas sobre o desempenho de ovinos Santa Inês. In: REUNIÃO ANUAL DA SOCIEDADE BRASILEIRA DE ZOOTECNIA, 39., 2002, Recife. Anais... Recife: Sociedade Brasileira de Zootecnia, 2002a. CD-ROM.

ALVES, K.S.; CARVALHO, F.F.R.; VÉRAS, A.S.C. Efeito dos níveis de energia em para ovinos Santa Inês sobre a digestibilidade aparente dos nutrientes. In: REUNIÃO ANUAL DA SOCIEDADE BRASILEIRA DE ZOOTECNIA, 39., 2002, Recife. Anais... Recife: Sociedade Brasileira de Zootecnia, 2002b. CD-ROM.

CARVALHO, S.R.S.T.; SIQUEIRA, R.S. Produção de ovinos em sistema de confinamento. In: SIMPÓSIO MINEIRO DE OVINOCULTURA: PRODUÇÃO DE CARNE NO CONTEXTO ATUAL, 1., 2001, Lavras. Anais... Lavras: Universidade Federal de Lavras, 2001. p.125-142.

BARROS, N.N.; SOUSA, F.B.; ARRUDA, F.A.V. Utilização de forrageiras e resíduos agroindustriais por caprinos e ovinos. Sobral: EMBRAPA - CNPC, 1997. 28p. (Documentos, 26)

DEMEYER, D.; DOREAU, M. Targets and procedures for altering ruminant meat and milk lipids. Proceedings of the Nutrition Society, v.58, n.3, p.593-607, 1999.

GARCIA, I.F.F.; BONAGURIO, S.; PÉREZ, J.R.O. Desempenho e características de carcaça de cordeiros de diferentes cruzamentos. In: REUNIÃO ANUAL DA SOCIEDADE BRASILEIRA DE ZOOTECNIA, 37., 2000, Viçosa, MG. Anais...Viçosa, MG: Sociedade Brasileira de Zootecnia, 2000. CDROM.
HASLER, C.M. Functional foods: their role in disease prevention and health promotion. Food Technology, v.52, n.2, p.57-62, 1998.

LUCHIARI FILHO, A. Perspectivas da bovinocultura de corte no Brasil. In: SIMPÓSIO SOBRE PRODUÇÃO INTENSIVA DE GADO DE CORTE, Campinas, 1998. Anais... Campinas: Colégio Brasileiro de Nutrição Animal, 1998. p.1-10.

MARQUES, C.A.T. Desempenho e características da carcaça de cordeiros criados com acesso em comedouros seletivos (creepfeeding) e terminados em confinamento. Jaboticabal: Universidade Estadual Paulista, 2003. 68p. Dissertação (Mestrado em Zootecnia) - Universidade Estadual Paulista, 2003.

MIR, Z.; RUSHFELD, M.L.; MIR, P.S. et al. Effect of dietary supplementation with either conjugated linoleic acid (CLA) or linoleic acid rich oil on the CLA content of lambs tissues. Small Ruminant Research, v.36, n.1, p.25-31. 2000.

PÉREZ, J.R.O.; GARCIA, I.F.F.; SILVA, R.H. et al. Desempenho de cordeiros Santa Inês e Bergamácia alimentados com diferentes níveis de dejetos de suínos. In: REUNIÃO ANUAL DA SOCIEDADE BRASILEIRA DE ZOOTECNIA, 35. 1998, Botucatu. Anais... Botucatu: Sociedade Brasileira de Zootecnia, 1998. p.173-175.

PREZIUSO, G.; RUSSO, C.; CASAROSA, L. et al. Effect of diet energy source on weight gain and carcass characterisitcs of lambs. Small Ruminant Research, v.33, n.3, p.9-15, 1999.

ROCHA, M.H.M.; SUSIN, I.; PIRES, A.V. et al. Desempenho de cordeiros terminados em confinamento alimentados com níveis crescentes de proteína. In: REUNIÃO ANUAL DA SOCIEDADE BRASILEIRA DE ZOOTECNIA, 38., 2001, Piracicaba. Anais... Piracicaba: Sociedade Brasileira de Zootecnia, 2001. p.1068-1069.

STATISTICAL ANALYSIS SYSTEMS - SAS. User's guide. Cary: 1996.

SILVA, D.J. Análise de alimentos (métodos químicos e biológicos). 2.ed. Viçosa, MG: Universidade Federal de Viçosa. 1990. 256p.

SNIFFEN, C.J.; CONNOR, J.D.; Van SOEST, P.J. A net carbohydrate and protein system for evalution cattle diets. II Carbohydrate and protein availability. Journal of Animal Science, v.70, n.3, p.3562-3577, 1992.

VILLAÇA, M.; EZEQUIEL, J.M.B.; KRONKA, S.N. Efeito de sementes oleaginosas inteiras e óleo de soja sobre a digestibilidade in vitro e padrões ruminais de bezerros holandeses. Revista Brasileira de Zootecnia, v.28, n.3, p.654-659, 1999. 